\title{
Review of the Prognosis Factors of COVID-19 Infection
}

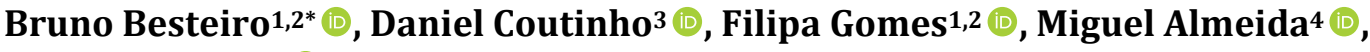 \\ Jorge Almeida ${ }^{1,2}$ () \\ ${ }^{1}$ Internal Medicine Department, Centro Hospitalar e Universitário de São João, Oporto, Portugal \\ ${ }^{2}$ Faculty of Medicine, Oporto University, Centro Hospitalar e Universitário de São João, Oporto, Portugal \\ ${ }^{3}$ Infectious Diseases Department, Centro Hospitalar de Vila Nova de Gaia Espinho, Vila Nova de Gaia, Portugal \\ ${ }^{4}$ General Surgery Department, Centro Hospitalar e Universitário de São João, Oporto, Portugal \\ Email: *bruno.besteiro4@gmail.com
}

How to cite this paper: Besteiro, B., Coutinho, D., Gomes, F., Almeida, M. and Almeida, J. (2021) Review of the Prognosis Factors of COVID-19 Infection. Advances in Infectious Diseases, 11, 196-215.

https://doi.org/10.4236/aid.2021.112019

Received: April 20, 2021

Accepted: June 8, 2021

Published: June 11, 2021

Copyright $\odot 2021$ by author(s) and Scientific Research Publishing Inc. This work is licensed under the Creative Commons Attribution International License (CC BY 4.0).

http://creativecommons.org/licenses/by/4.0/

\begin{abstract}
An epidemic of Coronavirus disease 2019 (COVID-19) outbroke in December 2019 in China, Wuhan, which is becoming a Public Health Emergency of International Concern. As this entity has become one of the worst infectious disease outbreaks of recent times, with mortality estimates in general population ranging from $1.4 \%$ to $8 \%$, it is crucial to better understand the prognostic factors which can be associated to the outcome of this disease. However, as the pandemic is still unfortunately under progression, there are limited data with regard to the prognostic factors. Hence, this review seeks to gather and provide the existing data of the literature of all the prognosis factors of COVID-19 infection such as older age, obesity, comorbidities, lymphocytopenia, d-dimers elevation, thrombocytopenia, elevated levels of high-sensitivity cardiac troponin, C-reactive protein elevation and imaging features of COVID-19.
\end{abstract}

\section{Keywords}

COVID-19, SARS-CoV-2, Prognosis, Outcome, Risk Factors

\section{Introduction}

Coronavirus disease 2019 (COVID-19) is caused by the severe acute respiratory syndrome coronavirus 2 (SARS-CoV-2), a new coronavirus type which was found to be the cause behind unexplained pneumonia cases around Wuhan, China in December 2019 [1].

The outbreak of COVID-19 had rapidly spread in China and even around the world resulting in numerous human casualties [2].

Despite the clinical features of COVID-19 having been reported, data regard- 
ing the prognostic factors associated with clinical outcomes are scarce. It is urgent to identify these in order to predict the outcome of this entity. Thus, the present article aims to review the prognostic factors of COVID-19 associated with the worst outcome, which might provide evidence for risk stratification, help improve clinical practice and reduce fatality. Moreover, Table 1 summurizes the major and most of recent studies' conclusions published in the literature.

\section{Prognostic Factors}

Based on the currently available information, the prognosis of SARS-CoV-2 infection seems to depend mostly on patient's characteristics, comorbidities, severity of clinical manifestations, laboratory test results and imaging.

Therefore, we chose to divide the risk factors into five different groups, describing each of them thoroughly.

\subsection{Patient Characteristics}

\subsubsection{Advanced Age}

A well-described poor prognosis factor exposed and sustained through many reports is older age. Its definition varies according to each study, with 50-year-old being the lower limit conveyed [1].

Wang et al. have demonstrated that older age increased the likelihood of death due to occurrence of a more severe pneumonia comparing to the younger [1].

In another study carried by the Chinese Center for Disease Control and Prevention, $80 \%$ of deaths occurred among adults $\geq 60$-year-old even in moderate disease. By opposition, young patients seemed to have a much better prognosis with milder disease occuring in most cases [2] [3]. Moreover, in an analysis from the United Kingdom, the risk of death among individuals $\geq 80$-year-old was 20 -fold higher than among individuals from 50 to 59-year-old [3]. In the United States, mortality was also higher among older individuals, with $80 \%$ of deaths occurring in those aged $\geq 65$ years-old. In contrast, individuals aged 18 to 34 years old accounted for only $5 \%$ of adults hospitalized due to COVID-19 in a large health care database study, giving rise to a mortality rate of $2.7 \%$ [4].

In what concerns the severe acute respiratory syndrome (SARS), older age is likely to be the most important predictor for the adverse prognosis in COVID-19 infected patients, with approximately half of the patients being over 50 years old in a study comprehending 8866 cases [5].

Pathophysiology can be explained by several mechanisms. Firstly, frailty and multiple comorbidities in the elderly increase the risk for pulmonary infection [6]. Secondly, the effects of aging on the immune system include reduced B and $\mathrm{T}$ cell production with diminished cellular function. Consequently, old individuals do not respond to immune challenge as robustly as young ones. Moreover, there is evidence of an age-related shift towards a type 2 cytokine profile. Together, all these manifestations lead to a deficiency in the control of viral replication and to more prolonged proinflammatory responses, resulting in a poor outcome [7]. 
Table 1. Prognosis markers associated with COVID-19 outcome.

\begin{tabular}{|c|c|c|c|c|}
\hline Prognosis factor & Author's & Number of patients & $\mathrm{p}$ value & Associated with a worse prognosis? \\
\hline \multirow{7}{*}{$\underline{\text { Older age }}$} & Wang L et al. [1] & $339 / 339$ patients $(100 \%)$ & $<0.001$ & Yes \\
\hline & Liu W et al. [6] & $15 / 78$ patients ( $\geq 60$ years) $(19.2 \%)$ & 0.011 & Yes \\
\hline & Zhou F et al. [7] & NA (total of 191 patients), MA 56 years & 0.0043 & Yes \\
\hline & Zhao X et al. [10] & NA (total of 53.000 patients), median age 49.8 & $<0.001$ & Yes \\
\hline & Zhang JJ et al. [25] & $98 / 140$ patients ( $\geq 50$ years) $(70 \%)$ & $<0.001$ & Yes \\
\hline & Wu C et al. [35] & NA (total of 201 patients) & $<0.001$ & Yes \\
\hline & Li K et al. [41] & NA (total of 83 patients), median age 45.5 & $<0.001$ & Yes \\
\hline \multirow{3}{*}{$\underline{\text { Sex }}$} & Zhao X et al. [10] & $29.150 / 53.000$ patients (M) (55\%) & $<0.001$ & Yes \\
\hline & Zhang JJ et al. [25] & $44 / 140$ patients (F) $(31.4 \%)$ & 0.219 & No \\
\hline & Wu C et al. [35] & $128 / 201$ patients $(63.7 \%)$ & $>0.005$ & No \\
\hline \multirow{5}{*}{$\underline{\mathrm{CVD}}$} & Wang L et al. [1] & $53 / 339$ patients $(15.6 \%)$ & $<0.001$ & Yes \\
\hline & Zhou F et al. [7] & $15 / 191$ patients $(7.9 \%)$ & 0.48 & No \\
\hline & Li K et al. [41] & $1 / 83$ patients $(1.2 \%)$ & $<0.001$ & Yes \\
\hline & Zhao X et al. [10] & $1431 / 53.000$ patients $(2.7 \%)$ & 0.002 & Yes \\
\hline & Zhang JJ et al. [25] & $7 / 140$ patients $(5.0 \%)$ & 0.448 & No \\
\hline \multirow{5}{*}{ Hypertension } & Wang L et al. [1] & $138 / 339$ patients ( $40.7 \%)$ & 0.031 & Yes \\
\hline & Li K et al. [41] & $5 / 83$ patients $(6.0 \%)$ & $<0.001$ & Yes \\
\hline & Zhao X et al. [10] & $10.070 / 53.000$ patients $(19.0 \%)$ & $<0.001$ & Yes \\
\hline & Zhang JJ et al. [25] & $42 / 140$ patients $(30.0 \%)$ & 0.085 & No \\
\hline & Wu C et al. [35] & $23 / 84$ patients $(27.4 \%)$ & 0.001 & Yes \\
\hline \multirow{4}{*}{$\underline{\mathrm{DM}}$} & Li K et al. [41] & $7 / 83$ patients $(8.4 \%)$ & $<0.001$ & Yes \\
\hline & Zhao X et al. [10] & $4346 / 53.000$ patients $(8.2 \%)$ & $<0.001$ & Yes \\
\hline & Zhang JJ et al. [25] & $17 / 140$ patients $(5.0 \%)$ & 0.615 & No \\
\hline & Wu C et al. [35] & $16 / 84$ patients $(19.0 \%)$ & 0.002 & Yes \\
\hline \multirow{3}{*}{ Smoking } & Liu W et al. [6] & $5 / 78$ patients $(6.4 \%)$ & 0.011 & Yes \\
\hline & Zhao X et al. [10] & NA (total 53.000 patients) & 0.663 & No \\
\hline & Zhang JJ et al. [25] & $9 / 140$ patients $(6.4 \%)$ & 0.448 & Yes \\
\hline \multirow{2}{*}{$\underline{\text { Malignancy }}$} & Wang L et al. [1] & $15 / 339$ patients $(4.4 \%)$ & 0.12 & No \\
\hline & Zhao X et al. [10] & NA (total 53.000 patients) & 0.309 & No \\
\hline \multirow{4}{*}{$\underline{\mathrm{COPD}}$} & Wang L et al. [10] & $21 / 339$ patients $(6.2 \%)$ & $<0.001$ & Yes \\
\hline & Li K et al. [41] & $5 / 83$ patients $(6.0 \%)$ & $<0.001$ & Yes \\
\hline & Zhao X et al. [10] & NA (total 53.000 patients) & 0.004 & Yes \\
\hline & Zhang JJ et al. [25] & $2 / 140$ patients $(1.4 \%)$ & 0.170 & No \\
\hline Eosinopenia & Zhang JJ et al. [25] & $73 / 138$ patients $(52.9 \%)$ & 0.165 & No \\
\hline \multirow{6}{*}{$\begin{array}{l}\text { Lymphocyte } \\
\text { count decreased }\end{array}$} & Wang L et al. [1] & NA (total of 339 patients) & $<0.001$ & Yes \\
\hline & Li K et al. [41] & $44 / 83$ patients $(53.0 \%)$ & $<0.001$ & Yes \\
\hline & Zhao X et al. [10] & $28.991 / 53.000$ patients $(54.7 \%)$ & $<0.001$ & Yes \\
\hline & Zhang JJ et al. [25] & $104 / 138$ patients $(75.4 \%)$ & 0.160 & No \\
\hline & Wu C et al. [35] & NA (total of 201 patients) & $<0.001$ & Yes \\
\hline & Du R-H et al. [51] & NA (total of 179 patients) & $<0.001$ & Yes \\
\hline \multirow{5}{*}{$\underline{\text { D-dimers }}$} & Wang L et al. [1] & NA (total of 339 patients) & $<0.001$ & Yes \\
\hline & Zhou F et al. [7] & NA (total of 191 patients) & 0.0033 & Yes \\
\hline & Zhao X et al. [10] & NA (total 53.000 patients) & $<0.001$ & Yes \\
\hline & Zhang JJ et al. [25] & $35 / 81$ patients ( $43.2 \%)$ & 0.004 & Yes \\
\hline & Wu C et al. [35] & NA (total of 201 patients) & $<0.05$ & Yes \\
\hline
\end{tabular}


Continued

\begin{tabular}{|c|c|c|c|c|}
\hline \multirow{4}{*}{$\underline{\mathrm{PT}}$} & Wang L et al. [1] & NA (total of 339 patients) & $<0.001$ & Yes \\
\hline & Zhao X et al. [10] & NA (total 53.000 patients) & 0.628 & No \\
\hline & Wu C et al. [35] & NA (total 201 patients) & $<0.01$ & Yes \\
\hline & Fogarty et al. [54] & NA (total of 83 patients) & 0.11 & No \\
\hline \multirow{2}{*}{$\frac{\text { Decreased blood }}{\text { platelets }}$} & Zhao X et al. [10] & NA (total 53.000 patients) & $<0.001$ & Yes \\
\hline & Lippi G et al. [57] & NA (total of 1779 patients) & $<0.001$ & Yes \\
\hline \multirow{4}{*}{ Elevated hs-TpI } & Wang L et al. [1] & NA (total of 339 patients) & $<0.001$ & Yes \\
\hline & Zhou F et al. [7] & NA (total of 191 patients) & 0.026 & Yes \\
\hline & Zhao X et al. [10] & NA (total 53.000 patients) & $<0.001$ & Yes \\
\hline & Du R-H et al. [43] & NA (total of 179 patients) & $<0.001$ & Yes \\
\hline \multirow{5}{*}{$\frac{\text { Procalcitonin }}{\text { increased }}$} & Wang L et al. [1] & NA (total of 339 patients) & $<0.001$ & Yes \\
\hline & Liu W et al. [6] & NA (total of 78) patients & 0.696 & No \\
\hline & Li K et al. [41] & $44 / 83$ patients (53.0\%) & 0.001 & Yes \\
\hline & Zhao X et al. [10] & NA (total 53.000 patients) & 0.007 & Yes \\
\hline & Zhang JJ et al. [25] & $41 / 118$ patients $(34.7 \%)$ & 0.004 & Yes \\
\hline \multirow{6}{*}{$\underline{\mathrm{CRP} \text { increased }}$} & Wang L et al. [1] & NA (total of 339 patients) & $<0.001$ & Yes \\
\hline & Liu W et al. [6] & NA (total of 78 patients) & 0.028 & Yes \\
\hline & Li K et al. [41] & $50 / 83$ patients $(60.2 \%)$ & 0.001 & Yes \\
\hline & Zhao X et al. [10] & NA (total 53.000 patients) & $<0.001$ & Yes \\
\hline & Zhang JJ et al. [25] & $125 / 136$ patients $(91.9 \%)$ & 0.199 & No \\
\hline & Wu C et al. [35] & NA (total of 201 patients) & 0.008 & Yes \\
\hline \multirow{4}{*}{$\frac{\text { Liver enzyme }}{\text { elevations }}$} & Wang L et al. [1] & NA (total of 339 patients) & $<0.001$ & Yes \\
\hline & Zhao X et al. [10] & NA (total 53.000 patients) & 0.001 & Yes \\
\hline & Wu C et al. [35] & NA (total of 201 patients) & $>0.05$ & No \\
\hline & Zhang Y et al. [68] & NA (total 115 patients) & 0.001 & Yes \\
\hline \multirow{3}{*}{ Albumin Levels } & Liu W et al. [6] & NA (total of 78 patients) & 0.003 & Yes \\
\hline & Zhao X et al. [10] & NA (total 53.000 patients) & 0.019 & Yes \\
\hline & Wu C et al. [35] & NA (total of 201 patients) & $<0.001$ & Yes \\
\hline
\end{tabular}

COPD: chronic obstructive pulmonar disease, CRP: $\mathrm{c}$ reative protein, CVD: cardiovascular disease, DM: diabetes mellitus, F: female, hS-TpI: high-sensitivity cardiac troponin T, M: male, NA: non atibutable, PT: prothrombin time.

Beyond its association with a worse prognosis by contributing to disease progression, it also seems to delay progression in recovery of COVID-19 [8].

\subsubsection{Gender}

Gender is also a well-established risk factor for severe COVID-19 outcome [3]. The existing literature shows that men are more likely to be infected than women, with over $90 \%$ of British deaths occurring in people over 60 , and $60 \%$ in men [1] [3] [9]. In fact, the majority of the reports have shown that men are more likely to be infected, this gender being identified as a predictor of severe disease and, therefore, demonstrating a higher mortality rate [9] [10].

This disparity between sexes is likely multifactorial and may be due to a higher expression of angiotensin-converting enzyme 2 (ACE2) receptor in males than that in females, due to lack of gene expression protective regulation by estrogen and X chromosome (as ACE2 is located in the X chromosome) [10] [11] [12]. 


\subsubsection{Obesity}

Obesity appears to be one of the most important predictors related to the severity of COVID-19 disease. One of the largest studies identifying obesity as a prominent risk factor, which analyzed data from more than 4000 COVID-19 patients, has demonstrated that obesity was one of the strongest hospitalization risk factors, body mass index $>40 \mathrm{~kg} / \mathrm{m}^{2}$ (odds ratio (OR) 6.2, 95\% confidence interval, CI, 4.2 - 9.3). The authors have also demonstrated its important role as a powerful predictor of COVID-19's outcome [3] [13].

Another study, which focused on patients under the age of 60 , found that those with obesity were twice as likely to be hospitalized and were at higher risk of requiring critical care. Surprisingly, it there was no demonstrated association between obesity and a severer disease in patients over 60 years [14].

In a systematic review, obesity was considered an independent risk and prognosis factor for disease severity as these population required an increase need for invasive mechanical ventilation. Therefore, aggressive treatment and prevention are recommended, since these individuals are considered a high-risk group [15].

Pathophysiology can be explained by many reasons. Firstly, obesity is a pro-inflammatory condition [13] in which the abnormal secretion of adipokines and cytokines, such as tumor necrosis factor (TNF), alfa and interferon, leads to immune dysfunction [16] [17], therefore contributing to increased morbidity in COVID-19 infection. Secondly, abdominal obesity is associated with a poor pulmonary function by decreased diaphragmatic excursion [18]. Thirdly, obesity interacts with insulin resistant states and the metabolic syndrome, promoting inflammatory and pro-thrombotic states that could lead to deleterious responses to infectious pathogens. Lastly, obese patients have more adipocytes, which, in turn, present a greater number of ACE2-expressing cells and, thus, SARS-CoV-2 is more likely to entry [17].

\subsection{Comorbidities}

\subsubsection{Hypertension}

Hypertension seems to be the most prevalent comorbidity in COVID-19 infection and is associated with a poor prognosis. In fact, hypertension is associated with ACE2 dysregulation, which could aggravate the imbalance caused by the infection [19].

According to a Chinese metanalysis based on 8 studies that included 46248 participants, hypertense patients demonstrated a higher risk of more agressive COVID-19 presentation (OR 2.36, CI 95\%, 1.46 - 3.83) [20]. The same result was also demonstrated in an another retrospective study with 1590 patients [21].

In addition, a different metanalysis including 1527 patients disclosed that hypertense individuals carried an augmented risk of requiring intensive care unit (ICU) treatment, with hypertensive states leading to worse prognosis (CI $=95 \%$, 1.54 - 2.68) [22].

\subsubsection{Diabetes Mellitus (DM)}

$\mathrm{DM}$ is one of the most characterized comorbidities related to this pulmonary in- 
fection [21] [22]. It should also be considered a risk factor for severe disease, acute respiratory distress syndrome (ARDS), rapid progression and a poor prognosis factor of COVID-19 as described by several studies [3] [17] [23] [24].

Additionally, in a study comprising 52 intensive care patients, DM was a comorbidity in $22 \%$ of 32 non-survivors [7]. In other studies of patients with severe disease, DM ranged from $12 \%$ to $16 \%$ suggesting the role of diabetes as a worsening prognostic factor [25]. Moreover, it appears that the incidence of COVID19 is two-fold in diabetic individuals [22].

These findings are explained by many reasons. Simply put, the greater frequency of infections in diabetic patients is caused by the hyperglycemic environment that favours immune dysfunction with reduced T cell response and neutrophil function [24] [26] [27].

\subsubsection{Smoking}

The mechanism of increased susceptibility to infections in smokers is multifactorial and includes the suppressive effects of cigarette smoke on the immune system [28]. However, there is scarce evidence in what concerns to smoking, with contradictory results.

On the one hand, in a systematic review of 5 studies aiming to evaluate the association between smoking and COVID-19 outcome, a higher disease severity was reported in active smokers, requiring most ICU admissions. In addition, death occurred more often among this population. The majority of the included studies concluded that smokers were 1.4 times more likely to have severe symptoms of COVID-19 and approximately 2.4 times more likely to be admitted to an ICU, need mechanical ventilation or die, compared to non-smokers [29].

On the other hand, a study that did not support these data was comprised in a meta-analysis which encompassing five studies with no significant association found between active smoking and COVID-19 severity (OR, 1.69; 95\% CI, 0.41 $6.92 ; \mathrm{p}=0.254)$. In this study, even after excluding the broadest of all five studies (which included $89.5 \%$ of the entire sample size), no statistically significant association was observed (OR, 4.35; $\mathrm{p}=0.129)$ [30].

Nevertheless, in a more recent meta-analysis, active smoking was significantly associated with the risk of severe COVID-19 infection. Hence, the most recent evidence suggests that smokers are more vulnerable to this entity [31].

\subsubsection{Cancer}

According to the literature, COVID-19 infection has a tremendous impact on cancer diagnosis, prognosis and therapeutic effects. However, results are contradictory as other studies also indicate that the percentages of COVID-19 infection and severe events in cancer patients are not higher compared to the general population [31].

Studies have shown that SARS-CoV-2 infected patients with cancer exhibit a steeper decline compared to those without this disease $(\mathrm{p}<0.001)$ [7]. They have also revealed poorer outcomes, due to higher incidence of acute complications 
[29] [31]. Moreover, Liang et al. reported that cancer patients had an increased risk of severe infections with a 3.5 -fold increase in the risk of ICU admission or death, compared to those without cancer [32] [33].

Notwithstanding, there are very few studies in the literature covering cancer patients and, thus, there is no certainty about its role in the outcome.

\subsection{Clinical Presentation}

Among patients with symptomatic COVID-19, some common symptoms that have been linked to COVID-19 include cough, myalgias and headache. Other features, comprising diarrhea, sore throat, and smell or taste abnormalities are also well-described. Pneumonia is the most frequent serious manifestation of infection, characterized primarily by fever, cough, dyspnea and bilateral infiltrates on chest imaging [34].

\section{ARDS}

Patients with COVID-19 are at risk for ARDS and death by respiratory failure. ARDS is a life-threatening complication of SARS-CoV-2 infection and predisposes to inferior outcomes.

Several risk factors for the development of ARDS and evolution to death have been analyzed and identified in quite a few studies. Age above 65 years old, neutrophilia, organ dysfunction and coagulation disturbances were all established as risk factors [35].

Likewise, Land Wang et al. provided strong evidence for ARDS as an extremely strong predictor of death in 339 patients with COVID-19. It was demonstrated that when ARDS occurred, the 28-day mortality would be near $50 \%$ [1].

It is also important to note that ARDS in different stages of COVID-19 patients causes diffuse alveolar damage in the lung. In the acute stage, there is hyaline membrane formation in the alveoli and this is followed by interstitial widening and by oedema. In the organising stage, fibroblast proliferation occurs [36] [37]. As patients move through the course of their illness, there seems to be more outcomes of ARDS are being reported, with lung fibrosis appearing as part of COVID - 19 ARDS. Ye Z reported that 17\% of patients had fibrous stripes in chest CT scans, and considered that the fibrous lesions may form during the healing of pulmonary chronic inflammation or proliferative diseases, with gradual replacement of cellular components by scar tissues [38].

\subsection{Laboratory Results}

\subsubsection{White Blood Cell Population}

\section{1) Lymphocytopenia}

Viral infections in the human body primarily involve damage to the immune system, resulting in a decline of the absolute lymphocyte number [6]. Additional studies have suggested that SARS-CoV-2 may impair the function of CD4+ helper and regulatory $\mathrm{T}$-cells and promote the initial hyperactivation which is fol- 
lowed by rapid exhaustion of cytotoxic CD8+ T-cells [39]. Hence, the degree of lymphocytopenia might indicate a more austere virus invasion which is likely to reflect the disease progression [40] and predicts the outcome [1].

Li et al. have investigated the clinical features associated with severe and critical COVID-19 pneumonia in 83 patients (25 of them severe cases). Lymphocyte count was decreased in $88 \%$ of critical patients vs. $37.9 \%$ in the control group (p $<0.001$ ). The lower absolute lymphocyte count in severe patients implied a more pronounced immunological disfunction, making it a useful index on the evaluation of disease severity [41]. Zhou $\mathrm{F}$ has also showed that baseline lymphocyte count was significantly higher in survivors than in non-survivors. Severe lymphopenia was observed until death in non-survivors and was more commonly observed in severe COVID-19 illness [7].

In addition, other studies observed that $\mathrm{CD} 4+$ and $\mathrm{CD} 8+$ lymphocyte counts were both significantly reduced in dead patients [1] [9] [42]. Also, Tan Li et al. stated that the lower the blood lymphocyte percentage was, the more severe is the disease. The authors have suggested that this marker could be used to classify the disease in moderate, severe, and critical ill types, based on the blood lymphocyte percentage (LYM\%), regardless of any other auxiliary indicators. They suggested to classify moderate disease if LYM\% > 20\%, severe if 5\% < LYM\% < $20 \%$ and critically ill patients if $\mathrm{LYM} \%<5 \%[40]$.

Moreover, in a prospective study, CD3 $+\mathrm{CD} 8+\mathrm{T}$-cells 75 cells $\mu \mathrm{L}^{-1}$ was a reliable predictor for mortality of patients with COVID-19 infection. It seems that $\mathrm{CD} 3+\mathrm{T}$-cells are the major type that is supressed in infected patients and this depletion is associated with an adverse outcome due to cytokine storm [43] [44].

\subsubsection{Coagulopathy}

The development of coagulopathy is one of the most significant poor prognostic features in patients who progress to multiple organ failure [45].

\section{1) D-dimers}

D-dimer elevation is a very common laboratory finding observed in COVID-19 patients, requiring hospitalization and predicting a poor prognosis [19] [42] [45] [46]. In fact, SARS-CoV-2 enters cells via ACE2 receptors, which are found in endothelial cells. This binding may lead to life-threatening micro and macrovascular thrombosis [47]. Data from literature suggest that the incidence of venous thromboembolism (VTE) can reach 25\% [48].

In the most in-depth analysis of clinical cases published to date, including data concerning 1099 SARS-CoV-2 positive patients from over 550 hospitals in China, D-dimers $\geq 0.5 \mathrm{mg} / \mathrm{L}$ were found in $260 / 560$ (46.4\%) of the patients tested. Among these, only $43 \%$ displayed raised D-dimers in case of non-severe disease, and about $60 \%$ had severe illness [49].

In another study, Tang identified markedly elevated D-dimers as one of the predictors of mortality. In fact, higher D-dimers levels probably indicate a severe inflammatory response accompanied by a secondary hypercoagulable state [45] [50]. Moreover, higher levels of D-dimers [2.12 $\mu \mathrm{g} / \mathrm{ml}$ (range 0.77 - $5.27 \mu \mathrm{g} / \mathrm{ml})]$ 
were observed in dead patients against survivors, who had a $0.61 \mu \mathrm{g} / \mathrm{ml}$ (range $0.35-1.29 \mu \mathrm{g} / \mathrm{ml}$ ). Additionally, a study carried by Huang demonstrated that patients who required ICU had higher D-dimer levels on admission (median D-dimer level $2.4 \mathrm{mg} / \mathrm{L}$ ) comparing to those who did not demand it (median D-dimer level $0.5 \mathrm{mg} / \mathrm{L}, \mathrm{p}=0.0042$ ) [45]. A different study also found a strong association between the elevation of $\mathrm{D}$-dimers and death during hospitalization $(\mathrm{p}=0.003)[7]$.

It is also important to refer that there is not yet a consensus on if and when patients should receive anticoagulation, what type and for how long [51]. In fact, Songpin et al. had studied the incidence of VTE in 81 patients requiring ICU admission. The group concluded that D-dimer $>1500 \mathrm{ng} / \mathrm{ml}$ had an $85 \%$ sensitivity and $88.5 \%$ specificity for predicting which patients would develop DVT. This study supported the concept of empiric anticoagulation for patients with markedly elevated $\mathrm{D}$-dimers as it cannot only predict thrombosis but also monitor the effectiveness of anticoagulants [52].

Moreover, the American Society of Hematology also reported that prophylactic dose enoxaparin is recommended for all hospitalized COVID-19 patients despite abnormal coagulation tests in the absence of active bleeding. Furthermore, it should only be held if platelet counts are less than $25 \times 109 / \mathrm{L}$, or if fibrinogen is less than $0.5 \mathrm{~g} / \mathrm{L}$. Nonetheless, it is also considered that therapeutic anticoagulation is not required unless another indication for therapeutic anticoagulation is documented (such as VTE, atrial fibrillation or mechanical valve) [53].

\section{2) Coagulation studies}

Patients with severe COVID-19 infection can develop a coagulopathy meeting criteria for Disseminated Intravascular Coagulopathy with fulminant activation of coagulation and consumption of coagulation factors. Tang demonstrated that a prolonged PT was found in the non-survivors when compared to survivors [45]. In what concerns to patients who needed ICU, a mild PT elevation was perceived when compared to ordinary patients [54]. In another study, it was reported that increased PT was associated with a higher risk of ICU, ARDS ( $\mathrm{p}<$ $0.001)$, a more severe disease $(\mathrm{p}=0.004)$ and death $(\mathrm{p}=0.001)$ [42] [46].

The hypercoagulable state observed in patients with COVID-19 can be explained by the dysfunction of endothelial cells induced by systemic pro-inflammatory cytokine, which results in excess thrombin generation and fibrinolysis shutdown [19] [55]. Furthermore, severe pneumonia induces hypoxia which can stimulate thrombosis through increasing blood viscosity and hypoxia-inducible transcription factor-dependent signaling pathway [56].

\section{3) Platelet count}

Thrombocytopenia is another predictor of COVID-19 severity that is independently associated with disease severity and risk of mortality [57].

In fact, thrombocytopenia can occur by direct infection of bone marrow cells by the virus, platelet destruction by the immune system or by platelet aggregation in the lungs resulting in microthrombi and platelet consumption [58]. 
Thrombocytopenia was identified as a significant risk factor for mortality and reported to occur in up to $55 \%$ of patients. Moreover, a low platelet count has long been recognized as an independent risk factor for sepsis-related mortality [57] as it correlates with multi-organ failure [59].

A meta-analysis of nine studies including 399 COVID-19 patients with severe disease showed that the platelet count was significantly lower in patients with more severe COVID-19. Subgroup analysis comparing patients by survival noted that lower platelet count correlated with mortality. Thrombocytopenia was also associated with over threefold enhanced risk of severe COVID-19 illness [42] [57] [59].

Therefore, based on the currently available literature, the measurement of these parameters in patients with COVID-19 should be performed not only for their documented prognostic value but also to help to stratifying the severity of the disease [42] [59].

\subsubsection{Elevated Levels of High-Sensitivity Cardiac Troponin}

The myocardial injury, defined in several studies by the increase in troponin levels, may be due to myocardial ischemia or non-ischemic cardiac events.

In a retrospective multicenter study, high serum sensitivity troponin I (hs-TpI) was measured during the clinical evolution of the majority of COVID-19 patients. An increase in hs-TpI levels was observed as a clinical worsening occurred, and a more significant rise was found in more than half of the patients who died. Therefore, it has been considered one of the biomarkers associated with in-hospital lethality. Concerning that same study, after comparing the patients who died to those who did not, the median level of hs-TnI was $8.8 \mathrm{pg} / \mathrm{mL}$ in casualties vs. 2.5 $\mathrm{pg} / \mathrm{mL}$ in survivors. During the follow-up period, the median hs-TnI value did not change significantly in those who survived $(2.5-4.4 \mathrm{pg} / \mathrm{mL})$. Contrarily, in non-survivors this value increased up to $290.6 \mathrm{pg} / \mathrm{mL}$ on day 22 , after the onset of symptoms [7].

In other cohort studies of COVID-19 patients, myocardial injury was documented in $7 \%-17 \%$ of hospitalized patients, being significantly more common among patients admitted to the ICU $(22.2 \%$ vs. $2.0 \%, \mathrm{p}<0.001)$ and in those who died (59\% vs. $1 \%, \mathrm{p}<0.0001)$. However, part of the increase in TpI levels may also be explained by kidney failure and, consequently, late troponin excretion, which is common in severe SARS-CoV-2 disease [60]. In addition, the analysis of six studies comprising patients with severe illness (defined by ICU admission, development of ARDS or death) showed that in these cases serum hs-TpI was markedly elevated [61].

In addition, the analysis of six studies of patients with severe illness (defined by ICU admission, development of ARDS or death) showed that in these cases serum hs-TpI was markedly elevated [60].

The underlying pathophysiological mechanisms of myocardial injury in COVID-19 are not yet fully understood. Acute myocardial infarction and direct damage to cardiomyocytes by the virus itself are among possible mechanisms 
that explain this process [60].

\subsubsection{Increased Amount of Inflammatory/Infection Markers 1) C-reactive protein (CRP) elevation}

CRP is an acute-phase reactant protein whose levels rise in response to inflammation correlating with severity. The link between CRP level with the severity and prognosis of COVID-19 is also reported in several studies [5] [62].

Ling $\mathrm{W}$ has similarly documented that, during COVID-19 early stages, CRP levels were positively correlated to lung lesions and could reflect disease severity [63]. This was also corroborated by Chen $\mathrm{W}$, who provided direct evidence that the level of CRP correlated to the severity of COVID-19 infection and could help to discern patients of moderate to severe COVID-19 infection from the mild ones. In addition, it could be an earlier indicator for severe illness and help physicians to stratify patients for ICU [64].

It is important to note that CRP values also seems to correlate with lung lesions, ARDS development, higher TpI levels and should be used as key indicator for disease monitoring [42] [62].

\subsubsection{Increased Amounts of Proinflammatory Cytokines in Serum}

It is well-known that whenever SARS-CoV-2 infects the respiratory tract, it can cause the release of pro-inflammatory cytokines. Additionally, more severe inflammatory reactions correlate with disease's severity [7]. In fact, in some cases of more serious infection, SARS-CoV-2 is associated with a cytokine "storm", characterized by increased plasma concentrations of IL-2, IL-7, IL-10, macrophage inflammatory protein 1 (MIP-1), granulocyte colony-stimulating factor (G-CSF), monocyte chemoattractant protein 1, interferon gamma-induced protein 10 (IP-10) and tumor necrosis factor (TNF). This marked elevation of inflammatory cytokines has been associated with pulmonary inflammation, extensive lung damage, clinical progression of extrapulmonary multi-organ collapse and a higher death rate [54] [65] [66]. The association with disease severity is also corroborated by another study, which reports that patients who required ICU admission had higher concentrations of these markers [41].

Among all these cytokines, IL- 6 and IL- 8 demonstrated that the most significant changes and their levels inversely correlate with lymphocyte count [44]. Wang et al. have equally provided evidence that cytokine release syndrome is a crucial factor in patients with SARS-CoV-2, leading to disease progression. It has also been shown that as the severity of the disease increases, the levels of IL-6 and IL-10 rise, too [67].

\subsubsection{Abnormal Liver Tests}

\section{1) Liver enzyme elevations and liver injury}

Liver damage in COVID-19 patients might be directly caused by the viral infection of liver cells.

Quite a few studies have exposed different degrees of elevated serum liver bi- 
ochemistries in COVID-19 patients, mainly indicated by abnormal alanine aminotransferase (ALT) and aspartate aminotransferase (AST) levels. In reality, the incidence of elevated ALT and AST ranged from 2.5\% - 53\% and 2.5\% $61.1 \%$, respectively. On the other hand, relevant elevations of alkaline phosphatase (AKP), gamma-glutamyl transferase (GGT) and total bilirubin (TB) levels have not been reported so far [68].

In a large cohort including 1099 patients, elevated levels of AST were present in $112(18.2 \%)$ of the non-severe individuals and in $56(39.4 \%)$ of severe disease cases [49]. Moreover, the proportion of abnormal ALT in serious cases $(28.11 \%)$ was higher than in mild cases (19.8\%). Similarly, Huang et al. reported that the proportion of liver injury in ICU patients (62\%) was greater than non-ICU patients (25\%) [54].

Contrarily, Wu et al. disclosed no significant differences in the liver function when comparing mild/moderate patients to severe ones [8]. Furthermore, Wang and colleagues analyzed 339 elderly COVID-19 patients and described that there were no evident differences in ALT levels between survivors and casualties ( $p>$ $0.05)$ [1]. In addition, cases of severe acute liver injury have rarely been mentioned [69].

Hence, abnormal liver function tests during the course of COVID-19 are common, though clinically significant liver injury is rare [70].

\section{2) Albumin Levels}

Low albumin levels have been consistently reported as a poor prognosis factor in COVID-19 patients [7] [68] [71].

Albumin is the most intuitive index of nutritional body status. When hypoalbuminemia occurs, body resistance to viruses lessens, leading to disease progression [6].

Huang et al. analyzed 36 non-survivors infected with SARS-CoV-2 and concluded that the majority presented decreased albumin (80.65\%) [72]. Similarly, Zhang and colleagues provided direct evidence that $77.8 \%$ of 82 deceased patients presented albumin $<40 \mathrm{~g} / \mathrm{L}$ [73].

Also, a recent study concluded that hypoalbuminemia was found to be a useful prognostic factor for severe patients with COVID-19. It was also associated with exacerbation of disease-associated inflammatory responses and progression of the disease [74].

\subsubsection{Laboratory Tests Indexes}

\section{1) Neutrophil-to-lymphocyte ratio}

In the clinical practice of treating patients with COVID-19, emerging evidences suggested that the neutrophil-to-lymphocyte ratio (NLR), an inflammatory index reflecting systemic inflammatory cascades, can be used as systemic inflammation marker.

Several studies have reported that this ratio could differentiate between $\mathrm{mild} /$ moderate and severe/critical groups and give the probability of death in patients with COVID-19. Moreover, current evidence suggests that NLR may 
also be a reliable predictor of COVID-19 progression and that an elevated NLR correlates with higher mortality [75].

In laboratory examination of COVID-19, lymphopenia is common. In severe or non-survival patients with COVID-19, the lymphocytes count decreases progressively, while the neutrophils count gradually increases (probably due to excessive inflammation and immune suppression caused by SARS-CoV-2 infection). On the one hand, neutrophils are generally regarded as pro-inflammatory cells, which can be triggered by virus-related inflammatory factors. On the other hand, systematic inflammation triggered by SARS-CoV-2 significantly depresses cellular immunity, leading to a decrease in $\mathrm{T}$ cells $(\mathrm{CD} 3+, \mathrm{CD} 4+$ and $\mathrm{CD} 8+\mathrm{T}$ cells). Hence, NLR can be easily calculated from peripheral blood routine tests and may be associated with the progression and prognosis of COVID-19 [75].

Other recent studies have also stated that the NLR was the most helpful independent prognostic biomarker in determining COVID-19 presence and the treatment efficacy. Besides, NLR had a higher diagnostic accuracy than other assessment tools, such as the CURB-65 [76].

NLR has good predictive values on disease severity and mortality in patients with COVID-19 infection [76]. NLR is readily calculated and cost-effective, which means clinicians can screen high-risk individuals earlier. This is especially desirable in settings experiencing healthcare resource scarcity [76]. Evaluating NLR can help clinicians identify potentially severe cases early, conduct early triage and initiate effective management in time, which may reduce the overall mortality of COVID-19 [75] as NLR could help in assessing the allocation of respiratory equipment in ICU patients and early evaluation of those in need of extracorporeal membrane oxygenation [76].

\section{2) $\mathrm{PaO}_{2} / \mathrm{FiO}_{2}$ ratio}

In COVID-19 infection, the lung is the most important organ invaded by SARS-CoV-2, several COVID-19 patients being characterized by hypoxia and respiratory distress. Hence, $\mathrm{PaO}_{2} / \mathrm{FiO}_{2}$ ratio, the most commonly used oxygenation index, is used in COVID-19 infection [77]. $\mathrm{PaO}_{2} / \mathrm{FiO}_{2}$ ratio is a widely used measure of hypoxemia in respiratory failure, calculated as the ratio between the arterial oxygen partial pressure $\left(\mathrm{PaO}_{2}\right)$ and the fractional inspired oxygen $\left(\mathrm{FiO}_{2}\right)$. This ratio was validated as a criterion for ARDS definition and severity [78].

An observational, prospective and multicenter study demonstrated that moderate-to-severe impairment in $\mathrm{PaO}_{2} / \mathrm{FiO}_{2}(<200 \mathrm{~mm} \mathrm{Hg})$ was independently associated with a threefold increase in risk concerning in-hospital mortality. The severity of respiratory failure assessed with the $\mathrm{PaO}_{2} / \mathrm{FiO}_{2}$ ratio is significantly associated with intubation rate and need for respiratory support. This study has also suggested that the severity of hypoxemia could be useful to triage patients with COVID-19 as well as to identify patients at higher risk of unfavorable outcomes [79].

In another study, $\mathrm{PaO}_{2} / \mathrm{FiO}_{2}$ ratio was significantly associated with prolonged hospital-stay. Moreover, the authors also reported that its use at the admission, 
so as to make a decision on the treatment intensity, as a single measurement, predicts a longer hospitalization [78].

\subsection{Imaging}

Chest CT can accurately evaluate the type and extent of lung lesions, as supported by Kunhua Li et al. who investigated the clinical and CT features associated with severe COVID-19 pneumonia. CT manifestations of COVID infection include ground glass opacities, consolidation, reticular patter, crazy-paving patterns and bronchial wall thickening (BWT) [41].

In what concerns to advanced disease, several studies have mentioned more frequent occurrence rates of consolidation, linear opacities, crazy-paving pattern, multiple lung lobe involvement, BWT and extrapulmonary lesions when compared to non-severe patients [41].

It was also determined that the presence of bilateral pneumonia and progressive radiographic deterioration on follow-up CT could have a roll as worst prognosis markers [9].

\section{Conclusions}

COVID-19 is emerging and spreading at an unprecedented rate, triggering a heavy impact worldwide. The present review has collected published data on COVID-19 prognostic factors and their correlation with SARS-CoV-2 infection outcomes. Nevertheless, further investigation is required to objectively confirm the clinical value of prognostic factors related to COVID-19.

As described throughout this article, the chronic diseases addressed are associated with an increased risk of severe clinical manifestation and, consequently, with a worse prognosis effect on the COVID-19 infection.

This review was developed not only in the hope of helping healthcare providers worldwide effectively recognize and deal with the 2019 SARS-CoV-2, but also to deliver a reference for future studies.

\section{Authors' Contributions}

All authors contributed to the conception of the Review. Bruno Besteiro concepted the study and drafted the manuscript; Daniel Coutinho and Filipa Gomes reviewed the literature and drafted the manuscript. Miguel Almeida and Jorge Almeida drafted the manuscript.

All authors agree to be accountable for all aspects of the work.

\section{Funding Sources}

No subsidies or grants contributed to this work.

\section{Conflicts of Interest}

The authors declare no conflicts of interest regarding the publication of this paper. 


\section{References}

[1] Wang, L., He, W.B., Yu, X.M., Hu, D.L., et al. (2020) Coronavirus Disease 2019 in Elderly Patients: Characteristics and Prognostic Factors Based on 4-Week Follow-Up. Journal of Infection, 80, 639-645. https://doi.org/10.1016/j.jinf.2020.03.019

[2] Wu, Z.Y. and McGoogan, J.M. (2020) Characteristics of and Important Lessons from the Coronavirus Disease 2019 (COVID-19) Outbreak in China: Summary of a Report of 72314 Cases from the Chinese Center for Disease Control and Prevention. JAMA, 323, 1239-1242. https://doi.org/10.1001/jama.2020.2648

[3] Williamson, E.J., Walker, A.J., Bhaskaran, K., Bacon, S., Bates, C., Morton, C.E., et al. (2020) Factors Associated with COVID-19-Related Death Using OpenSAFELY. Nature, 584, 430-436. https://doi.org/10.1038/s41586-020-2521-4

[4] Cunningham, J.W., Vaduganathan, M., Claggett, B.L., Jering, K.S., Bhatt, A.S., Rosenthal, N., et al. (2020) Clinical Outcomes in Young US Adults Hospitalized with COVID-19. JAMA Internal Medicine, 181, 379-381.

https://doi.org/10.1001/jamainternmed.2020.5313

[5] Yi, Y., Lagniton, P., Ye, S., Li, E. and Xu, R.H. (2020) COVID-19: What Has Been Learned and to Be Learned about the Novel Coronavirus Disease. International Journal of Biological Sciences, 16, 1753-1766. https://doi.org/10.7150/ijbs.45134

[6] Liu, W., Tao, Z.W., Wang, L., Yuan, M.-L., Liu, K., Zhou, L., et al. (2020) Analysis of Factors Associated with Disease Outcomes in Hospitalized Patients with 2019 Novel Coronavirus Disease. Chinese Medical Journal, 133, 1032-1038. https://doi.org/10.1097/CM9.0000000000000775

[7] Zhou, F., Yu, T., Du, R., Fan, G., Liu, Y., Liu, Z., et al. (2020) Clinical Course and Risk Factors for Mortality of Adult in Patients with COVID-19 in Wuhan, China: A Retrospective Cohort Study. The Lancet, 395, 1054-1062. https://doi.org/10.1016/S0140-6736(20)30566-3

[8] Zhou, F., Yu, T., Du, R., Fan, G., Liu, T., Liu, Z., et al. (2020) Early Antiviral Treatment Contributes to Alleviate the Severity and Improve the Prognosis of Patients with Novel Coronavirus Disease (COVID-19). Journal of Internal Medicine, 288, 128-138. https://doi.org/10.1111/joim.13063

[9] Du, Y., Tu, L., Zhu, P., Mu, M., Wang, R., Yang, P., et al. (2020) Clinical Features of 85 Fatal Cases of COVID-19 from Wuhan: A Retrospective Observational Study. American Journal of Respiratory and Critical Care Medicine, 202, 300. https://doi.org/10.2139/ssrn.3546088

[10] Zhao, X., Zhan, B., Li, P., Ma, C., Gu, J., Hou, P., et al. (2020) Incidence, Clinical Characteristics and Prognostic Factor of Patients with COVID-19: A Systematic Review and Meta-Analysis.

[11] Liu, J., Ji, H., Zheng, W., Wu, X., Zhu, J.J., Arnold, A.P., et al. (2010) Sex Differences in Renal Angiotensin Converting Enzyme 2 (ACE2) Activity Are 17 $\beta$-Oestradiol-Dependent and Sex Chromosome-Independent. Biology of Sex Differences, 1, 6. https://doi.org/10.1186/2042-6410-1-6

[12] Hoffmann, M., Kleine-Weber, H., Schroeder, S., Kruger, N., Herrler, T., Erichsen, S., et al. (2020) SARS-CoV-2 Cell Entry Depends on ACE2 and TMPRSS2 and Is Blocked by a Clinically Proven Protease Inhibitor. Cell, 181, 271-280.e8. https://doi.org/10.1016/j.cell.2020.02.052

[13] Petrilli, C., Jones, S.A. and Yang, J. (2020) Factors Associated with Hospitalization and Critical Illness among 4,103 Patients with Covid-19 Disease in New York City. https://doi.org/10.1101/2020.04.08.20057794 
[14] Lighter, J., Phillips, M., Hochman, S., Sterling, S., Johnson, D., Francois, F., et al. (2020) Obesity in Patients Younger than 60 Years Is a Risk Factor for Covid-19 Hospital Admission. Clinical Infectious Diseases, 71, 896-897. https://doi.org/10.1093/cid/ciaa415

[15] Tamara, A. and Tahapary, L. (2020) Obesity as a Predictor for a Poor Prognosis of COVID-19: A Systematic Review. Diabetology \& Metabolic Syndrome, 14, 655-659. https://doi.org/10.1016/j.dsx.2020.05.020

[16] Heredia, F.P., Gómez-Martínez, S. and Marcos, A. (2012) Obesity, Inflammation and the Immune System. Proceedings of the Nutrition Society, 71, 332-338. https://doi.org/10.1017/S0029665112000092

[17] Bello-Chavolla, O.Y., Bahena-López, J.P., Antonio-Villa, N.E., Vargas-Vázquez, A., González-Díaz, A., Márquez-Salinas, A., et al. (2020) Predicting Mortality Due to SARS-CoV-2: A Mechanistic Score Relating Obesity and Diabetes to COVID-19 Outcomes in Mexico. The Journal of Clinical Endocrinology and Metabolism, 105, dgaa346. https://doi.org/10.1210/clinem/dgaa346

[18] Dietz, W. and Burgoa-Santos, C. (2020) Obesity and Its Implications for COVID-19 Mortality. Obesity (Silver Spring), 28, 1005. https://doi.org/10.1002/oby.22818

[19] Lazzaroni, M.G., Piantoni, S., Masneri, S., Garrafa, E., Martini, G., Tincani, A., et al. (2020) Coagulation Dysfunction in COVID-19: The Interplay between Inflammation, Viral Infection and the Coagulation System. Blood Reviews, 2020, Article ID: 100745. https://doi.org/10.1016/j.blre.2020.100745

[20] Yang, J., Zheng, Y., Gou, X., Pu, K., Chen, Z. and Guo, Q. (2020) Prevalence of Comorbidities in the Novel Wuhan Coronavirus (COVID-19) Infection: A Systematic Review and Meta-Analysis. International Journal of Infectious Diseases, 94, 91-95. https://doi.org/10.1016/j.ijid.2020.03.017

[21] Guan, W.J., Liang, W.H., Zhao, Y., Liang, H.R., Chen, Z.S., Li, Y.M., et al. (2020) Comorbidity and Its Impact on 1590 Patients with Covid-19 in China: A Nationwide Analysis. European Respiratory Journal, 55, Article ID: 2000547. https://doi.org/10.1183/13993003.00547-2020

[22] Li, B., Yang, J., Zhao, F., Zhi, L., Wang, X., Liu, L., et al. (2020) Prevalence and Impact of Cardiovascular Metabolic Diseases on COVID-19 in China. Clinical Research in Cardiology, 109, 531-538. https://doi.org/10.1007/s00392-020-01626-9

[23] Guo, W., Li, M., Dong, Y., Zhou, H., Zhang, Z., Tian, C., et al. (2020) Diabetes Is a Risk Factor for the Progression and Prognosis of COVID-19. Diabetes/Metabolism Research and Reviews, 36, e3319. https://doi.org/10.1002/dmrr.3319

[24] Huang, I., Lim, M.A. and Pranata, R. (2020) Diabetes Mellitus Is Associated with Increased Mortality and Severity of Disease in COVID-19 Pneumonia-A Systematic Review, Meta-Analysis, and Meta-Regression. Diabetology \& Metabolic Syndrome, 14, 395-403. https://doi.org/10.1016/j.dsx.2020.04.018

[25] Zhang, J.J., Dong, X., Cao, Y.Y., Yuan, Y.D., Yang, Y.B., Yan, Y.Q., et al. (2020) Clinical Characteristics of 140 Patients Infected with SARS-CoV-2 in Wuhan, China. Allergy, 75, 1730-1741. https://doi.org/10.1111/all.14238

[26] Ferlita, S., Yegiazaryan, A., Noori, N., Lal, G., Nguyen, T., To, K., et al. (2019) Type 2 Diabetes Mellitus and Altered Immune System Leading to Susceptibility to Pathogens, Especially Mycobacterium tuberculosis. Journal of Clinical Medicine, 8 , 2219. https://doi.org/10.3390/jcm8122219

[27] Jafar, N., Edriss, H. and Nugent, K. (2016) The Effect of Short-Term Hyperglycemia on the Innate Immune System. The American Journal of the Medical Sciences, 351, 201-211. https://doi.org/10.1016/j.amjms.2015.11.011 
[28] Arcavi, L. and Benowitz, N.L. (2004) Cigarette Smoking and Infection. Archives of Internal Medicine, 164, 2206-2216. https://doi.org/10.1001/archinte.164.20.2206

[29] Vardava, C.I. and Nikitara, K. (2020) COVID-19 and Smoking: A Systematic Review of the Evidence. Tobacco Induced Diseases, 18, 20. https://doi.org/10.18332/tid/119324

[30] Lippi, G. and Henry, B.M. (2020) Active Smoking Is Not Associated with Severity of Coronavirus Disease 2019 (COVID-19). European Journal of Internal Medicine, 75, 107-108. https://doi.org/10.1016/j.ejim.2020.03.014

[31] Guo, F.R. (2020) Active Smoking Is Associated with Severity of Coronavirus Disease 2019 (COVID-19): An Update of a Meta-Analysis. Tobacco Induced Diseases, 18, 37. https://doi.org/10.18332/tid/121915

[32] Liu, C., Zhao, Y., Okwan-Duodu, D., Basho, R. and Cui, X. (2020) COVID-19 in Cancer Patients: Risk, Clinical Features, and Management. Cancer Biology \& Medicine, 17, 519-527. https://doi.org/10.20892/j.issn.2095-3941.2020.0289

[33] Al-Quteimat, O.M. and Amer, A.M. (2020) The Impact of the COVID-19 Pandemic on Cancer Patients. American Journal of Clinical Oncology, 43, 452-455. https://doi.org/10.1097/COC.0000000000000712

[34] Wang, D., Hu, B., Hu, C., Zhu, F., Liu, X., Zhang, J., et al. (2020) Clinical Characteristics of 138 Hospitalized Patients with 2019 Novel Coronavirus-Infected Pneumonia in Wuhan, China. JAMA, 323, 1061-1069. https://doi.org/10.1001/jama.2020.1585

[35] Wu, C., Chen, X., Cai, Y., Xia, J., Zhou, X., Xu, S., et al. (2020) Risk Factors Associated with Acute Respiratory Distress Syndrome and Death in Patients with Coronavirus Disease 2019 Pneumonia in Wuhan, China. JAMA Internal Medicine, 180, 934-943. https://doi.org/10.1001/jamainternmed.2020.0994

[36] Xu, Z., Shi, L., Wang, Y., Zhang, J., Huang, L., Zhang, C., et al. (2020) Pathological Findings of COVID-19 Associated with Acute Respiratory Distress Syndrome. The Lancet Respiratory Medicine, 8, 420-422. https://doi.org/10.1016/S2213-2600(20)30076-X

[37] Tian, S., Xiong, Y., Liu, H., Niu, L., Guo, J., Liao, M., et al. (2020) Pathological Study of the 2019 Novel Coronavirus Disease (COVID-19) through Postmortem Core Biopsies. Modern Pathology, 33, 1007-1014. https://doi.org/10.1038/s41379-020-0536-x

[38] Ye, Z., Zhang, Y., Wang, Y., Huang, Z. and Song, B. (2020) Chest CT Manifestations of New Coronavirus Disease 2019 (COVID-19): A Pictorial Review. European Radiology, 30, 4381-4389. https://doi.org/10.1007/s00330-020-06801-0

[39] Bhatraju, P.K., Ghassemieh, B.J., Nichols, M., Kim, R., Jerome, K.R., Nalla, A.R., et al. (2020) Covid-19 in Critically Ill Patients in the Seattle Region-Case Series. The New England Journal of Medicine, 382, 2012-2022. https://doi.org/10.1056/NEJMoa2004500

[40] Tan, L., Wang, Q., Zhang, D., Ding, J., Huang, Q., Tang, Y.Q., et al. (2020) Lymphopenia Predicts Disease Severity of COVID-19: A Descriptive and Predictive Study. Signal Transduction and Targeted Therapy, 5, 33. https://doi.org/10.1038/s41392-020-0148-4

[41] Li, K., Wu, J., Wu, F., Guo, D., Chen, L., Fang, Z., et al. (2020) The Clinical and Chest CT Features Associated with Severe and Critical COVID-19 Pneumonia. Investigative Radiology, 55, 327-331. https://doi.org/10.1097/RLI.0000000000000672

[42] Terpos, E., Ntanasis-Stathopoulos, I., Elalamy, I., Kastritis, E., Sergentanis, T.N., Politou, M., et al. (2020) Hematological Findings and Complications of COVID-19. 
American Journal of Hematology, 95, 834-847. https://doi.org/10.1002/ajh.25829

[43] Du, R.H., Liang, L.R., Yang, C.Q., Wang, W., Cao, T.Z., Li, M., et al. (2020) Predictors of Mortality for Patients with COVID-19 Pneumonia Caused by SARS-CoV-2: A Prospective Cohort Study. European Respiratory Journal, 55, Article ID: 2000524. https://doi.org/10.1183/13993003.00524-2020

[44] Zhang, X., Tan, Y., Ling, Y., Lu, G., Liu, F., Yi, Z., et al. (2020) Viral and Host Factors Related to the Clinical Outcome of COVID-19. Nature, 583, 437-440. https://doi.org/10.1038/s41586-020-2355-0

[45] Barrett, C.D., Moore, H.B., Yaffe, M.B. and Moore, E.E. (2020) ISTH Interim Guidance on Recognition and Management of Coagulopathy in COVID-19: A Comment. Journal of Thrombosis and Haemostasis, 18, 2060-2063. https://doi.org/10.1111/jth.14860

[46] Luo, L., Xu, M., Du, M., Kou, H., Liao, D., Cheng, Z., et al. (2020) Early Coagulation Tests Predict Risk Stratification and Prognosis of COVID-19. Aging (Albany NY), 12, 15918-15937. https://doi.org/10.18632/aging.103581

[47] Arentz, M., Yim, E., Klaff, L., Lokhandwala, S., Riedo, F.X., Chong, M. and Lee, M. (2020) Characteristics and Outcomes of 21 Critically Ill Patients with COVID-19 in Washington State. JAMA, 323, 1612-1614. https://doi.org/10.1001/jama.2020.4326

[48] Fogarty, H., Townsend, L., Cheallaigh, C.N., Bergin, C., Martin-Loeches, I., Browne, P., et al. (2020) COVID19 Coagulopathy in Caucasian Patients. British Journal of Haematology, 189, 1044-1049. https://doi.org/10.1111/bjh.16749

[49] Guan, W.J., Ni, Z., Hu, Y., Liang, W.H., Ou, C.Q., He, J.X., et al. (2020) Clinical Characteristics of Coronavirus Disease 2019 in China. The New England Journal of Medicine, 382, 1708-1720. https://doi.org/10.1056/NEJMoa2002032

[50] Al-Ani, F., Chehade, S. and Lazo-Langner, A. (2020) Thrombosis Risk Associated with COVID-19 Infection. A Scoping Review. Thrombosis Research, 192, 152-160. https://doi.org/10.1016/j.thromres.2020.05.039

[51] Stony Brook Anticoagulation Protocol for COVID-19 Patients. http://www.sages.org/wp-content/uploads/2020/04/SB-Anticoagulation-Plan-for-C OVID-19-patients.pdf

[52] Cui, S., Chen, S., Li, X., Liu, S. and Wang, F. (2020) Prevalence of Venous Thromboembolism in Patients with Severe Novel Coronavirus Pneumonia. Journal of Thrombosis and Haemostasis, 18, 1421-1424. https://doi.org/10.1111/jth.14830

[53] American Society of Hematology (2020) COVID-19 and Coagulopathy: Frequently Asked Questions. http://www.hematology.org/covid-19/covid-19-and-coagulopathy

[54] Huang, C., Wang, Y., Li, X., Ren, L., Zhao, J., Hu, Y., et al. (2020) Clinical Features of Patients Infected with 2019 Novel Coronavirus in Wuhan, China. The Lancet, 395, 497-506. https://doi.org/10.1016/S0140-6736(20)30183-5

[55] Levi, M. and Van der Poll, T. (2017) Coagulation and Sepsis. Thrombosis Research, 149, 38-44. https://doi.org/10.1016/j.thromres.2016.11.007

[56] Gupta, N., Zhao, Y.Y. and Evans, C.E. (2019) The Stimulation of Thrombosis by Hypoxia. Thrombosis Research, 181, 77-83.

https://doi.org/10.1016/j.thromres.2019.07.013

[57] Lippi, G., Plebani, M. and Henry, B.M. (2020) Thrombocytopenia Is Associated with Severe Coronavirus Disease 2019 (COVID-19) Infections: A Meta-Analysis. Clinica Chimica Acta, 506, 145-148. https://doi.org/10.1016/j.cca.2020.03.022

[58] Xu, P., Zhou, Q. and Xu, J. (2020) Mechanism of Thrombocytopenia in COVID-19 Patients. Annals of Hematology, 99, 1205-1208. 
https://doi.org/10.1007/s00277-020-04019-0

[59] Becker, R.C. (2020) COVID-19 Update: Covid-19-Associated Coagulopathy. Journal of Thrombosis and Thrombolysis, 50, 54-67.

https://doi.org/10.1007/s11239-020-02134-3

[60] Driggin, E., Madhavan, M.V., Bikdeli, B., Chuich, T., Laracy, J., Biondi-Zoccai, G., et al. (2020) Cardiovascular Considerations for Patients, Health Care Workers, and Health Systems during the Coronavirus Disease 2019 (COVID-19) Pandemic. Journal of the American College of Cardiology, 75, 2352-2371. https://doi.org/10.1016/j.jacc.2020.03.031

[61] Lippi, G., Lavie, C.J. and Sanchis-Gomar, F. (2020) Cardiac Troponin I in Patients with Coronavirus Disease 2019 (COVID-19): Evidence from a Meta-Analysis. Progress in Cardiovascular Diseases, 63, 390-391. https://doi.org/10.1016/j.pcad.2020.03.001

[62] Potempa, L.A., Rajab, I.M., Hart, P.C., Bordon, J. and Fernandez-Botran, R. (2020) Insights into the Use of C-Reactive Protein as a Diagnostic Index of Disease Severity in COVID-19 Infections. American Journal of Tropical Medicine and Hygiene, 103, 561-563. https://doi.org/10.4269/ajtmh.20-0473

[63] Wang, L. (2020) C-Reactive Protein Levels in the Early Stage of COVID-19. Médecine et Maladies Infectieuses, 50, 332-334. https://doi.org/10.1016/j.medmal.2020.03.007

[64] Chen, W., Zheng, K.I., Liu, S., Yan, Z., Xu, C. and Qiao, Z. (2020) Plasma CRP Level Is Positively Associated with the Severity of COVID-19. Annals of Clinical Microbiology and Antimicrobials, 19, 18. https://doi.org/10.1186/s12941-020-00362-2

[65] Castelli, V., Cimini, A. and Ferri, C. (2020) Cytokine Storm in COVID-19: "When You Come Out of the Storm, You Won't Be the Same Person Who Walked in". Frontiers in Immunology, 11, 2132. https://doi.org/10.3389/fimmu.2020.02132

[66] Fara, A., Mitrev, Z., Rosalia, R.A. and Assas, B.M. (2020) Cytokine Storm and COVID-19: A Chronicle of Pro-Inflammatory Cytokines. Open Biology, 10, Article ID: 200160. https://doi.org/10.1098/rsob.200160

[67] Wang, L.S., Wang, Y., Ye, D. and Liu, Q. (2020) A Review of the 2019 Novel Coronavirus (COVID-19) Based on Current Evidence. International Journal of Antimicrobial Agents, 55, Article ID: 105948. https://doi.org/10.1016/j.ijantimicag.2020.105948

[68] Zhang, Y., Zheng, L., Liu, L., Zhao, M., Xiao, J. and Zhao, Q. (2020) Liver Impairment in COVID-19 Patients: A Retrospective Analysis of 115 Cases from a Single Center in Wuhan City, China. Liver International, 40, 2095-2103. https://doi.org/10.1111/liv.14455

[69] Xu, L., Liu, J., Lu, M., Yang, D. and Zheng, X. (2020) Liver Injury during Highly Pathogenic Human Coronavirus Infections. Liver International, 40, 998-1004. https://doi.org/10.1111/liv.14435

[70] Garrido, I., Liberal, R. and Macedo, G. (2020) Review Article: COVID-19 and Liver Disease-What We Know on 1st May. Alimentary Pharmacology \& Therapeutics, 52, 267-275. https://doi.org/10.1111/apt.15813

[71] Wan, S., Xiang, Y., Fang, W., Zheng, Y., Li, B., Hu, Y., et al. (2020) Clinical Features and Treatment of COVID-19 Patients in Northeast Chongqing. Journal of Medical Virology, 92, 797-806. https://doi.org/10.1002/jmv.25783

[72] Huang, Y., Yang, R., Xu, Y. and Gong, P. (2020) Clinical Characteristics of 36 Non-Survivors with COVID-19 in Wuhan, China.

https://doi.org/10.1101/2020.02.27.20029009 
[73] Zhang, B., Zhou, X., Qiu, Y., Feng, F., Feng, J., Jia, Y., et al. (2020) Clinical Characteristics of 82 Death Cases with COVID-19. https://doi.org/10.1371/journal.pone.0235458

[74] Lin, L., Hu, K., Cai, S., Deng, X., Shao, X., Liang, Y., et al. (2020) Hypoproteinemia Is an Independent Risk Factor for the Prognosis of Severe COVID-19 Patients. Journal of Clinical Biochemistry and Nutrition, 67, 126-130. https://doi.org/10.3164/jcbn.20-75

[75] Li, X., Liu, C., Mao, Z., Xiao, M., Wang, L., Qi, S. and Zhou, F. (2020) Predictive Values of Neutrophil-to-Lymphocyte Ratio on Disease Severity and Mortality in COVID-19 Patients: A Systematic Review and Meta-Analysis. Critical Care, 24, 647. https://doi.org/10.1186/s13054-020-03374-8

[76] Alkhatip, A., Kamel, M.G., Hamza, M.K., Farag, E.M., Yassin, H.M., Elayashy, M., Naguib, A.A., Wagih, M., Abd-Elhay, F.A., Algameel, H.Z., Yousef, M.A., Purcell, A. and Helmy, M. (2021) The Diagnostic and Prognostic Role of Neutrophil-to-Lymphocyte Ratio in COVID-19: A Systematic Review and Meta-Analysis. Expert Review of Molecular Diagnostics. https://doi.org/10.1080/14737159.2021.1915773

[77] Gu, Y., Wang, D., Chen, C., Lu, W., Liu, H., Lv, T., Song, Y. and Zhang, F. (2021) $\mathrm{PaO}_{2} / \mathrm{FiO}_{2}$ and IL-6 Are Risk Factors of Mortality for Intensive Care COVID-19 Patients. Scientific Reports, 11, Article No. 7334. https://doi.org/10.1038/s41598-021-86676-3

[78] Zinellu, A., De Vito, A., Scano, V., Paliogiannis, P., Fiore, V., Madeddu, G., Maida, I., Zinellu, E., Mangoni, A.A., Arru, L.B., Carru, C., Babudieri, S., Pirina, P. and Fois, A.G. (2021) The $\mathrm{PaO}_{2} / \mathrm{FiO}_{2}$ Ratio on Admission Is Independently Associated with Prolonged Hospitalization in COVID-19 Patients. Journal of Infection in Developing Countries, 15, 353-359. https://doi.org/10.3855/jidc.13288

[79] Santus, P., Radovanovic, D., Saderi, L., Marino, P., Cogliati, C., De Filippis, G., Rizzi, M., Franceschi, E., Pini, S., Giuliani, F., Del Medico, M., Nucera, G., Valenti, V., Tursi, F. and Sotgiu, G. (2020) Severity of Respiratory Failure at Admission and In-Hospital Mortality in Patients with COVID-19: A Prospective Observational Multicentre Study. BMJ Open, 10, e043651.

https://doi.org/10.1136/bmjopen-2020-043651 